\title{
Optimizing Investment in Two-Sided Platforms
}

\author{
Tian-Tian Yang ${ }^{1}$, Xiao Xuan ${ }^{2}$, Wen-Ya Huang ${ }^{2}$, Wen-Qi Duan ${ }^{2 *}$ \\ ${ }^{1}$ College of Internet Economy, Jinhua Polytechnic, Jinhua 321017, CHINA \\ ${ }^{2}$ College of Economics and Management, Zhejiang Normal University, Jinhua 321004, CHINA
}

Received 18 April 2017 • Revised 16 August 2017 • Accepted 27 September 2017

\begin{abstract}
Platform owners need to manage its internal cash flow as investments on buyer side and on seller side. Investment on buyer side will increase using experiences and investment on seller side can create an atmosphere of innovation. It is much necessary to allocate and optimize the total investment on each side users so as to obtain maximal profit. A three-period game model is developed to find the optimal investment decision. And during the process, we find that platforms can be divided into four kinds as investment non-sensitive platform, Seller-sensitive platform, Buyersensitive platform, and Investment sensitive platform. It is also found that the platform system structure influences the distribution of total value on platform owner, buyer side, and seller side.
\end{abstract}

Keywords: two-sided platform, optimal investment decision, invest-non-sensitive, seller-sensitive, buyer-sensitive

\section{INTRODUCTION}

Recent years, "two-sided market" is so hot that companies go "platform". With Alibaba's IPO surged 38\% in its first day on the New York Stock Exchange, platform industry has became a real catch, yet it's a risky approach for the big up-front investment. Not only researchers pushing sophisticated problems, like pricing problem from within a platform to multinational intra-firm pricing (Schindler and Schjelderup, 2010), business operators in different industries pursuing transformation and upgrading from traditional business style to platform model. Platform investment decision is an important managerial field, but received rare researcher's attention except for Anderson, Parker, and Tan (2014), who examined platform performance investment in markets that exhibits twosided network externalities. Platforms should spend their resources to increasingly differentiate themselves from others. With more investment on buyer side, platform gets to attract buyers more, with better using experiences buyer group expand, attracting more sellers (Li and Liu, 2010). On the other hand, with more investment on seller side, sellers will have more support of a better condition to start innovation and creation (Tsai \& Lei, 2016). So the problem platform owners facing here is how to divide total investment between buyer side and seller side. Following this train of thought, we look into the internal cash flow of a platform solving for the best investment decision of the platform on buyer side and seller side.

As buyers and sellers act differently when facing same amount of investment platform throws, in this paper, we use economic idea to build a model following three-step solving approach with game theory and at last seek for the best architecture of the platform. We can find that when buyers and sellers are sensitive to platform's investment, the platform will get more profit. On the other hand, buyers will gain more when they are not sensitive to platform's investment. While buyers are sensitive to platform's investment but sellers are not, sellers will get more. Therefore, an optimal investment strategy is put forward as follow: Non-sensitive part gets more utilities, which is the subsidy from the system. Besides, cross-sided interaction will increase system's the whole utility. A clever way for platform owners is to rising user interactions, such as increasing traffic and giving privileges.

(C) Authors. Terms and conditions of Creative Commons Attribution 4.0 International (CC BY 4.0) apply. 


\section{Contribution of this paper to the literature}

- Our findings contribute to the optimal investment for two-sided platforms. We believe that invest buyer side will increase buyers using experiences and invest for sellers can inspire innovation and creation. Further, according to their sensitiveness, divides platform system into four kinds as invest non-sensitive platform, seller-sensitive platform, buyer-sensitive platform, and invest sensitive platform.

- This paper also has practical implications. Specifically, invest sensitive platform's utility grows with utility decrease of buyer side and seller side. In addition, buyers gain more utility on invest non-sensitive platform and it's better for sellers when it is a buyer-sensitive platform.

\section{MODEL FORMULATION}

When platform owners make big efforts to keep their user bases, it's vital to know how much buyer side needs, how much seller side needs and how much platform needs to sacrifice their requires. We are aware of that investing for buyer side will improve the using experience of platform for buyers and investing for seller side can strengthen their service innovation and competitiveness. In this case, platform owners are facing the paradox to decide the best investment proportion. When platform invest on buyer side, buyers get better service and their number base will stay and grow. With cross-sided network effects, increasing number of buyers lead to more sellers, which will expands the number of platform interactions. On the other hand, when investing on seller side, sellers enjoy better infrastructure services which ease their way through innovation and increase their ability of competition (Wang, 2016). In return, competitive sellers will attract more buyers on the platform and with cross-sided effects both parties grow big, so is the platform. Therefore, the final question for platform owner is to decided how much money for buyer side to further their using experience and how much invest for seller side to improve their innovation and competition.

\section{Assumptions and Implications}

In developing our research model, we take reference of Katsamakas (2004) for the established model and with Armstrong's (2006) research foundation, we set the platform profit and buyer and seller utilities using mathematical forms. The model considers cross-sided externalities only, as they are the most typical effects. Moreover, this design only works under circumstances where the two sides do not negotiate away the corresponding usage and membership externalities. The design decisions will determine the right investment strategy of internal cash flow of the platform.

The assumptions are as follows: (1) Platforms gain revenue from buyers' fees, sellers' fees and their interactions. The revenue gained by offering a service is further assumed to be linear in the number of end-users, which is a common assumption in the network economic literature and enables us to characterize the equilibrium in detail. (2) The investment for buyers and sellers will yield out same level of improvement for both qualities. Invest in buyers will provide better using experiences and invest for sellers give them a better atmosphere for innovation and creation. So we are here to assume that same invest yield out same improvement of their utilities. (3) The buyers and the sellers enjoy network externalities from each other and the improved utility will exert an influence on both parties.

The platform is an intermediated network connecting two parties, the buyer side and the seller side. The number of buyers and sellers participating on the platform is assumed to be $n_{b}$ and $n_{s}$, respectively. The total number of buyers and sellers in the market is read as $N_{b}$ and $N_{s}$. So the users join the platform is known as fraction $x_{b}=n_{b} / N_{b}$ and $y_{s}=n_{s} / N_{s}$. Buyers and sellers enjoy network externalities from each other, separately, and both are heterogeneous to the respective valuation of network externality, $\theta \in[0,1]$ as buyers and $\tau \in[0,1]$ as sellers. Their participation prices are set as $p_{b}$ and $p_{s}$ by the platform.

\section{Platform Profits}

Platform owner aims to maximize profit, which can be the guidance of following models. Buyers and sellers get on board pay for platform fee as $p_{b}$ and $p_{s}$, respectively. The number of buyers and sellers on board is known as $x_{b}$ and $y_{s}$. Adding buyer-seller interactions into consideration, platform gains profit through transactions between buyers purchasing sellers' services. It depends on the activity of both sides, which is represented by $\lambda$ and generated by the interaction of the two sides on the platform (Roberto 2005) as a single-interaction externality. Crossinteraction revenue is denoted as $\lambda x_{b} y_{s}$. Platform invest for two parts: invest on buyer side as $V_{b}$ and invest on seller side as $V_{s}$. Therefore, the profit (utility) of the platform is given as:

$$
\pi_{p}=p_{b} x_{b}+p_{s} y_{s}+\lambda x_{b} y_{s}-\left(V_{b}+V_{s}\right)
$$




\section{Buyer Utility}

Buyers react differently when facing the same amount of platform investments. Some buyers are sensitive to platform's investment, a little improve will be much helpful, e.g. Search engine. Simplify of the ranking for users to find what they are looking for will certainly increase their utility a lot. However, some buyers are not sensitive to platform's investments. It may cost a lot for them to get a little bit improvement, e.g. mature shopping websites. If they want to impress their customers, they need to prepare a fortune. So much so that buyers are different under various platforms. So we divide buyers into invest-sensitive type and non-invest-sensitive type. Buyer utility is given by

$$
U_{b}=\beta\left(V_{b}\right) \theta y_{s}-p_{b}
$$

Here, $\beta\left(V_{b}\right) \theta y_{s}$ indicates the benefits that buyers gain from services provided by sellers on the platform. Because of linear network externalities, $\beta$ represents the profitability buyers gain through the interaction. So when investment for buyers increase, its ability of absorbing profits gains. Then, we have $\beta\left(V_{b}\right)$, as platform investment for buyers will increase its ability of gaining utility. Also, buyers are heterogeneity, which is demonstrated in how they value the platform and sellers' services through cross-sided externality. The term $\theta$ is a random variable that explains heterogeneity in how buyers value different services, and is uniformly distributed on [0,1]. With better services offered by platforms, buyers can enhance their using experience and increase utility.

\section{Seller Utility}

Sellers also act differently when facing platform investments. Some sellers are sensitive to platform's investment, little invest will stimulate large scale of innovation and creation, ie. Newly booming O2O websites or cell phone apps, call for little invest of the platform but can yield out lots of harvests. However, not all sellers are sensitive to platforms' investment. As Windows and Apple, platform costs millions to get new technology improvements. We divide sellers into invest-sensitive type and non-invest-sensitive type, as well. Sellers' utility is given by

$$
U_{s}=\alpha\left(V_{s}\right) \tau x_{b}-p_{s}
$$

Here, $\alpha\left(V_{b}\right) \tau x_{b}$ indicates the revenue gained by the $x_{b}$ buyers that joined the platform and $\alpha$ represents the profitability of sellers. Due to linear network externalities, we can characterize $\alpha$ in detail as denoting the marginal externality benefit associated with each buyer. When platform invest on sellers, sellers' ability of gaining profits increase. $\tau$ explains heterogeneity and is distributed on [0,1]. The figure below shows sellers' gaining ability and platform's investments.

\section{SOLUTION METHODOLOGY}

The platform owner aims to decide the best investment choice for its internal cash flow. This paper models the decision behaviors of platform users, platform operator and platform owner with a three-period game, to get the optimal internal management decision for platform owners finding the optimal investment for both parties and acquire the optimal profits.

Platform owners decided how to divide invest for both sides. On the one hand, with the invest on buyer side as $V_{b}$ and invest on seller side as $V_{s}$, which attracts buyers and sellers on board, on the other hand, platform owner charge entrance fees from buyers and sellers as $p_{b}$ and $p_{s}$. buyers and sellers choose whether to get on the platform at the price or not, getting the balanced number $x_{b}$ and $y_{s}$. With cross-sided externalities, more buyers attract more sellers, which then leads to more buyers. We solve the problem following progresses in Figure 4. Firstly, we solve for equilibrium numbers of $x_{b}^{*}$ and $y_{s}^{*}$. Then searching for equilibrium prices $p_{b}^{*}$ and $p_{s}^{*}$. Finally get the optimal decision of the investment.

\section{Platform Users}

Platform attracts buyers and sellers only if they can get positive utility, with rational or impulsive decisions. We fist solve for the equilibrium answer of $x_{b}$ and $y_{s}$ as $x_{b}^{*}$ and $y_{s}^{*}$.

Given $p_{b}, p_{s}$, the value $\hat{\theta}$ of marginal buyer who is indifferent of joining the platform or not is $\left(U_{b}=0\right)$

$$
\hat{\theta}=\frac{p_{b}}{\beta\left(V_{b}\right) y_{s}^{*}}
$$

Buyers go for positive utility, which leads to $x_{b}>\hat{\theta}$, for $\theta \in[0,1]$, we then get:

$$
1-\hat{\theta}=x_{b}
$$


From Eq.(4) and Eq.(5), we get

$$
p_{b}=\beta y_{s}^{*}\left(1-x_{b}^{*}\right)
$$

The normalized and relabeled parameters are in Appendix, which explains at equilibrium, $x_{b}=x_{b}^{*} ; y_{s}=y_{s}^{*}$. 0)

Similarly, for sellers, the value $\tau$ of the marginal seller who is indifferent of joining the platform or not is $\left(U_{s}=\right.$

$$
\hat{\tau}=\frac{p_{s}}{\alpha\left(V_{s}\right) x_{b}}
$$

Sellers ask for positive utility as well, which means $Y_{s}\langle\hat{\tau}$, as $\tau \in[0,1]$, then

$$
1-\hat{\tau}=y_{s}
$$

From Eq.(7) and Eq.(8), we get

$$
p_{s}=\alpha x_{b}^{*} \quad\left(1-y_{s}^{*}\right)
$$

\section{Platform Operator}

After getting the platform users, we seek for the price $p_{b}$ and $p_{s}$ to get the maximize profit.

$$
\pi_{p}=p_{b} x_{b}+p_{s} y_{s}+\lambda x_{b} y_{s}-\left(V_{b}+V_{s}\right) ; X^{*} \in[0,1], Y^{*} \in[0,1]
$$

With Eq.(6) and Eq.(9),The optimal answer goes for :

$$
\begin{aligned}
& \frac{\partial \pi_{p}}{\partial x_{b}^{*}}=\beta y_{s}^{*}-2 \beta x_{b}^{*} y_{s}^{*}+\alpha y_{s}^{*}-\alpha y_{s}^{* 2}+\lambda Y_{s}^{*}=0 \\
& \frac{\partial \pi_{p}}{\partial y_{s}^{*}}=\beta X_{b}^{*}-\beta X_{b}^{*^{2}}+\alpha X_{b}^{*}-2 \alpha x_{b}^{*} y_{s}^{*}+\lambda X_{b}^{*}=0
\end{aligned}
$$

We can solve the above equations and get the optimal $X_{b}^{*}$ and $Y_{s}^{*}$ :

$$
\begin{aligned}
& x_{b}^{*}=\frac{\alpha+\beta+\lambda}{3 \beta} \\
& y_{s}^{*}=\frac{\alpha+\beta+\lambda}{3 \alpha}
\end{aligned}
$$

Then with Eq.(13) and Eq.(14), the optimal $p_{b}^{*}$ and $p_{s}^{*}$ goes as:

$$
\begin{aligned}
& p_{b}^{*}=\frac{(\alpha+\beta+\lambda)(2 \beta-\alpha-\lambda)}{9 \alpha} \\
& p_{s}^{*}=\frac{(\alpha+\beta+\lambda)(2 \alpha-\beta-\lambda)}{9 \beta}
\end{aligned}
$$

\section{Platform Owner}

Using the results of the above four equilibrium elements, the platform will be able to plan how to choose its service. Solving for $\frac{\partial \pi_{p}}{\partial V_{b}}=0$ and $\frac{\partial \pi_{p}}{\partial V_{s}}=0$, the optimal investment decision satisfies:

$$
\begin{aligned}
& \frac{\partial \beta}{\partial V_{b}}=\frac{27 \alpha \beta^{2}}{3 \beta(\alpha+\beta+\lambda)^{2}-(\alpha+\beta+\lambda)^{3}} \\
& =\frac{27 \alpha\left(V_{s}\right) \beta\left(V_{b}\right)^{2}}{3 \beta\left(V_{b}\right)\left(\alpha\left(V_{s}\right)+\beta\left(V_{b}\right)+\lambda\right)^{2}-\left(\alpha\left(V_{s}\right)+\beta\left(V_{b}\right)+\lambda\right)^{3}} \\
& \frac{\partial \alpha}{\partial V_{s}}=\frac{27 \alpha^{2} \beta}{3 \alpha(\alpha+\beta+\lambda)^{2}-(\alpha+\beta+\lambda)^{3}} \\
& =\frac{27 \alpha\left(V_{s}\right)^{2} \beta\left(V_{b}\right)}{3 \alpha\left(V_{s}\right)\left(\alpha\left(V_{s}\right)+\beta\left(V_{b}\right)+\lambda\right)^{2}-\left(\alpha\left(V_{s}\right)+\beta\left(V_{b}\right)+\lambda\right)^{3}}
\end{aligned}
$$

Above Eq.(17) and Eq.(18) shows the exact point when investment on buyer side and investment on seller side get to the optimal situation. When the uprising of buyers use experience and nurture sellers' innovation and creation, then it reach a balanced point. Platform owners can take this model as a guiding tip, which will help them approach the optimal profit. 


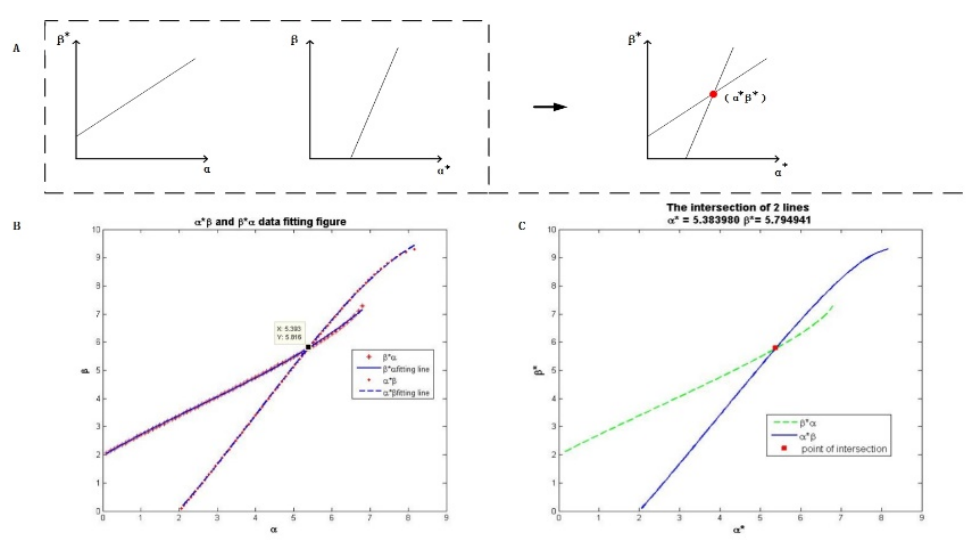

Figure 1. First solve for number set $\left(\boldsymbol{\alpha}, \boldsymbol{\beta}^{*}\right)$, then solve for number set $\left(\boldsymbol{\alpha}^{*}, \boldsymbol{\beta}\right)$, getting $\left(\boldsymbol{\alpha}^{*}, \boldsymbol{\beta}^{*}\right)$. Read from first pic that the number is $(5.393,5.816)$ and draw the fitting line in second pic keep tolerance as $10^{-5}$ to make the answer more accurate as $(5.3840,5.7949)$

Table 1. Platform's profit

\begin{tabular}{|c|c|c|c|c|}
\hline & \multirow[b]{2}{*}{ Profit situation } & \multicolumn{3}{|c|}{ Invest non-sensitive $\longrightarrow$ Invest sensitive } \\
\hline \multirow{2}{*}{$\begin{array}{l}\text { Invest non- } \\
\text { sensitive }\end{array}$} & & $\alpha=\frac{10}{1+1500^{*} e^{-7 * V S}}$ & $\alpha=\frac{10}{1+1500^{*} e^{-8^{*} \sqrt{s}}}$ & $\alpha=\frac{10}{1+1500 * e^{-9 * \sqrt{s}}}$ \\
\hline & $\beta=\frac{10}{1+1200^{*} e^{-4^{*} V b}}$ & 1.2316 & 1.3654 & 1.4688 \\
\hline & $\beta=\frac{10}{1+1200^{*} e^{-5^{*} V b}}$ & 1.5986 & 1.7444 & 1.8322 \\
\hline Invest sensitive & $\beta=\frac{10}{1+1200^{*} e^{-6^{*} V b}}$ & 1.8383 & 1.9812 & 2.0701 \\
\hline
\end{tabular}

\section{ANALYSIS}

The optimal investment policy towards internal money flow depends on two equations. We will first solve for the answers fits the first equation, which is the left side of the equation fits the right side of the equation. Taken Eq.(17) for example, we will get $\frac{\partial \beta}{\partial V_{b}}=\frac{27 \alpha\left(V_{S}\right) \beta\left(V_{b}\right)^{2}}{3 \beta\left(V_{b}\right)\left(\alpha\left(V_{s}\right)+\beta\left(V_{b}\right)+\lambda\right)^{2}-\left(\alpha\left(V_{s}\right)+\beta\left(V_{b}\right)+\lambda\right)^{3}}$ solve for $\left(\alpha, \beta^{*}\right)$. As mentioned before, we use logistic curve to describe the influence of invest form platform exert on the users' ability of gaining profits. Similarly, we solve Eq.(18) to get number set of $\left(\alpha^{*}, \beta\right)$. Then the point we are looking for is the intersection point.

We search for the optimal answer through the process displayed in Figure 1. Firstly, we solve equation for number set $\left(\alpha, \beta^{*}\right)$, then solve equation for number set $\left(\alpha^{*}, \beta\right)$. These two lines get the crossing point that fits both as $\left(\alpha^{*}, \beta^{*}\right)$. The left fitting figure is the number set and we read the number from the fitting line. The right intersection of 2 lines is the computer drawing fitting line and then we get the crossing point under the tolerance of $10^{-5}$. We can see that from first pic we read the number is $(5.393,5.816)$ and the second is $(5.3840,5.7949)$, which improves the accuracy. We use computer fitting the two lines to get the crossing point, making the answer more accurate.

\section{Proposition1: when buyers and sellers are sensitive to platforms' invest, platform gets more profit}

From Table 1 we can see that when $\beta$ holds still, sellers go from invest non-sensitive to invest sensitive, platform's profit increase. When $\alpha$ holds still, buyers go from invest non-sensitive to invest sensitive, platform's profit increase. Buyers and sellers are both sensitive to platform's investment, while platform's investment will make a difference to buyer's using experience and seller's innovation and creation. The interaction is quickly. We call these platforms invest-sensitive platform. When those buyers and sellers both are not sensitive to platform's investment, we call these platforms invest-non-sensitive platform. Invest-sensitive platforms make more profits than invest-non-sensitive platforms. 


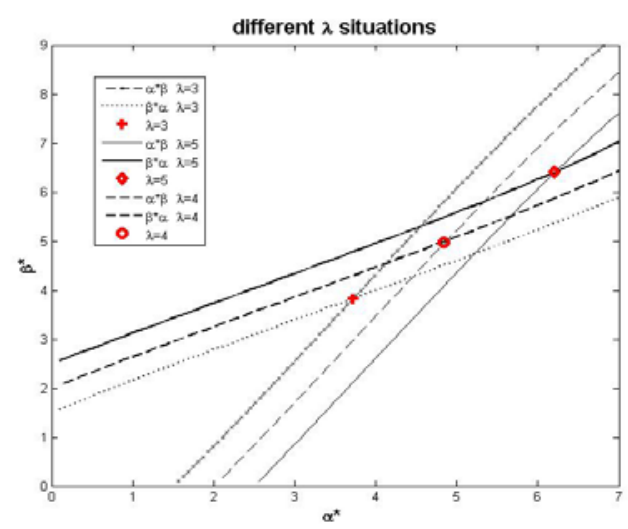

Figure 2. Different $\lambda^{\prime}$ 's situation. We draw 6 lines as the crossing point of $\alpha^{*} \beta$ and $\beta^{*} \alpha$ when $\lambda=3$, the crossing point of $\alpha^{*} \beta$ and $\beta^{*} \alpha$ when $\lambda=4$, the crossing point of $\alpha^{*} \beta$ and $\beta^{*} \alpha$ when $\lambda=5$. As from the picture, the crossing point rise as $\lambda$ increase.

(1) There always exert the optimal investment policy for platform owner. What platform owners need is to follow the right path.

(2) When sellers are sensitive to platform's investment, platform's profit grows.

(3) When buyers are sensitive to platform's investment, platform's profit grows.

(4) Invest-sensitive platform gets more profits.

\section{Proposition 2: cross-sided interaction will increase system's whole utility}

We choose $\alpha=\frac{10}{1+1500 * e^{-9 * V s}}$ and $\beta=\frac{10}{1+1200 * e^{-6 * V b}}$, when platform's profit becomes maximize, for buyer side and seller side both are sensitive to platform's invest, as the ideal situation for a platform. With $\lambda$ changing from 3 to 5, platform's profit increase from 1.1959 to 2.9441. At the same time, buyer utility increase from 3.4268 to 5.7632 and seller utility increase from 3.1235 to 5.1680 . It's obvious that increasing cross-sided interaction can enhance the effectiveness of the overall system.

\section{Proposition 3: buyers gain more utility when it's not sensitive to platform's investment}

When $\beta$ holds still, buyer utility does not change much with seller's ability of gaining profit grow. Yet, when buyer is not sensitive to platform's investment, as sellers grow more flexible to platform's profit, buyer utility decrease. When buyer is sensitive to platform's investment, as sellers grow more nimble to platform's investment, buyer utility will increase and then decrease. As buyer and sellers both becoming more sensitive to platform's invest, buyer utility decrease. Also, when $\alpha$ holds still, with buyer change from invest non-sensitive to invest sensitive, buyer utility will decrease. Buyers gain more utility when it is not sensitive to invest form platform.

\section{Proposition 4: While buyer is sensitive to platform's invest and seller is not, sellers will get more utility}

When $\beta$ holds still, buyer is not sensitive to platform's investment, seller's ability of gaining profits decrease with the reacting to platform's investments. And when buyer becoming sensitive to platform's invest, seller's utility of gaining profits decrease then increase, but is weakened overall as changing from non-sensitive to platform's investment to sensitive.

From the above analyze, we can see that there exert an optimal invest policy for platform owners, when it can maximize its profits. When buyers and sellers are sensitive to platform's investment, platform's utility grows with buyer side and seller side's utility decrease. As the total utility in the market keeps still, stand for platform owners, they are more fond of buyers and sellers who are sensitive to their investment. As for buyer side, it will gain more utility when both parties are not sensitive to platform's invest. As for seller side, it gains more utility when buyer side is sensitive and seller side is not to platform's investment. 
Table 2. Buyer utility

\begin{tabular}{|c|c|c|c|c|}
\hline & & Invest non-sensitive & $\rightarrow$ Invest sensit & \\
\hline \multirow{2}{*}{$\begin{array}{l}\text { Invest non- } \\
\text { sensitive }\end{array}$} & Buyer utility & $\alpha=\frac{10}{1+1500^{*} e^{-7 * V s}}$ & $\alpha=\frac{10}{1+1500^{*} e^{-8^{*} \sqrt{s}}}$ & $\alpha=\frac{10}{1+1500^{*} e^{-9^{*} V / s}}$ \\
\hline & $\beta=\frac{10}{1+1200^{*} e^{-4^{*} V b}}$ & 5.1914 & 5.1627 & 5.1492 \\
\hline \multirow{2}{*}{$\begin{array}{c}\downarrow \\
\text { Invest } \\
\text { sensitive }\end{array}$} & $\beta=\frac{10}{1+1200^{*} e^{-5^{*} V b}}$ & 4.6613 & 4.7938 & 4.6916 \\
\hline & $\beta=\frac{10}{1+1200^{*} e^{-6^{*} \sqrt{b}}}$ & 4.4547 & 4.6294 & 4.5013 \\
\hline
\end{tabular}

Table 3. Sellers' utility

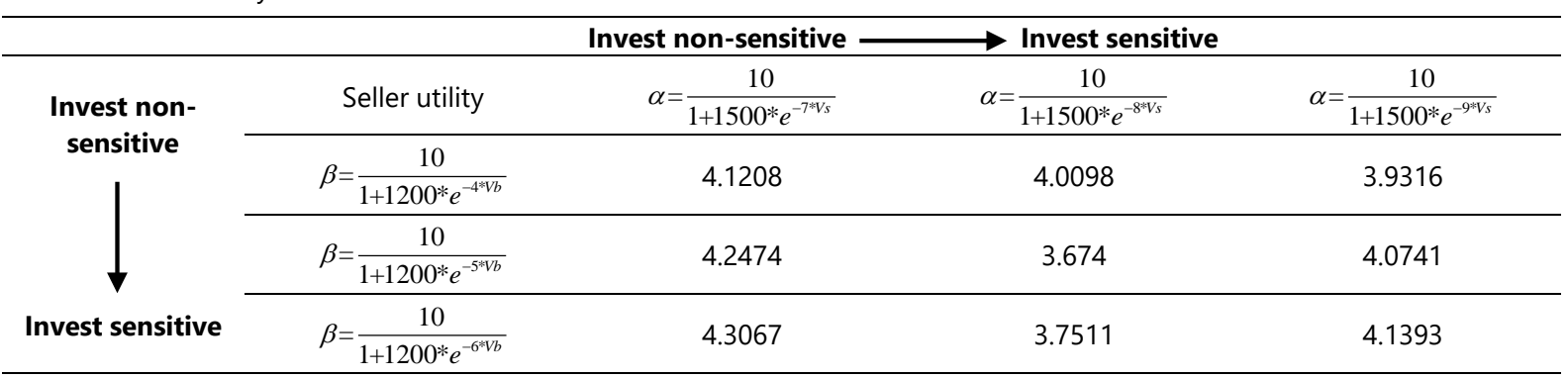

\section{MANAGEMENT INSPIRATION}

We take the above conclusion into consideration. (1) When platform is invest non-sensitive platform, as iphone's technology and WINDOWS, both requires a lot of investments on buyer side and seller side to make a difference, will benefit buyers most. As a matter of fact, mobile industry launch app ecosystem, accounting for $18 \%$ of the combined app services and handset market. The innovation and creation of iphone's culture makes it the leader of information and technology. (2) When platform is invest sensitive platform as O2O operators and cellphone app developers, they gain large profits over a short time, as Groupon, Didi Taxi, ect. (3) When platform's buyer side is not sensitive to platform's investment and seller side is sensitive to its investment, this platform is seller-sensitive platform. These platforms are more of traditional media enterprises as newspapers, when readers are not so easily touched yet, advertisers do. Minjae Song (2011) using data on TV magazines in Germany show that magazines set copy prices below marginal costs and earn profits from selling ad pages. (4) When platform's seller side is not sensitive to its invest and buyer side is sensitive, we call this platform buyer-sensitive platform, as search engine, where sellers, in this case, advertisers, will be the winner in the market. As for platform owners, it's kind of important to look for buyers and sellers who are sensitive to its investments. So that when it is investing for an improvement, the information will transmit to both sides and both parties will actually start to make things better. Moreover, there will always be an invest point where platform owners can get the optimal outcome, so follow the right policy matters.

\section{CONCLUSION}

This paper studies the internal cash flow of a platform to invest between buyer side and seller side to yield out the optimal utility. As invest for buyer side will increase buyers using experiences and invest for sellers can inspire innovation and creation. During work, we divided platform system into four kinds as invest non-sensitive platform, Seller-sensitive platform, Buyer-sensitive platform, and Invest sensitive platform, depending on whether buyer side or seller side is sensitive to platform's investment. We get the conclusions as follows: First, there exert an optimal invest policy for platform owners, when it can maximize its profits. Besides, invest sensitive platform's utility grows with utility decrease of buyer side and seller side. Last but not least, buyers gain more utility on invest non-sensitive platform and it's better for sellers when it is a Buyer-sensitive platform.

\section{ACKNOWLEDGEMENT}

This research was supported by National Natural Science Foundation of China under Grant No. 71271193 and 71571165, Zhejiang Provincial Natural Science Foundation of China under Grant No. LZ14G010001. 


\section{REFERENCES}

Anderson, Jr. E. G., Parker, G. G., \& Tan, B. (2014). Platform performance investment in the presence of network externalities [J]. Information Systems Research, 25(1), 152-172.

Armstrong, M. (2006). Competition in two-sided markets [J]. The RAND Journal of Economics, 37(3), 668-691.

Filistrucchi, L., Geradin, D., Van Damme, E. (2012). Identifying two-sided markets [J]. Dipartimento di Scienze Economiche Università di Firenze, working paper series, (1).

Gawer, A. (2014). Bridging differing perspectives on technological platforms: Toward an integrative framework [J]. Research Policy.

Hsieh, J. K., \& Hsieh, Y. C. (2013). Appealing to Internet-based freelance developers in smartphone application marketplaces [J]. International Journal of Information Management, 33(2), 308-317.

Katsamakas, E., \& Bakos, Y. (2004). Design and ownership of two-sided networks: implications for Internet intermediaries [J]. Journal of Management Information Systems, 25(2), 171-202.

Kemper, A. (2010). Valuation of network effects in software markets [J]. A complex networks approach. Contributions to Management Science.

Li, S., Liu, Y., \& Bandyopadhyay, S. (2010). Network effects in online two-sided market platforms: A research note [J]. Decision Support Systems, 49(2), 245-249.

Liu, Q., \& Serfes, K. (2013). Price Discrimination in Two-Sided Markets [J]. Journal of Economics \& Management Strategy, 22(4), 768-786.

Martini, A. (2013). Managing Speed in Companies Developing Large-Scale Embedded Systems [M]//Software Business. From Physical Products to Software Services and Solutions. Springer Berlin Heidelberg, 231-232.

McIntyre, D. P., \& Chintakananda, A. (2014). Competing in network markets: Can the winner take all? [J]. Business Horizons, 57(1), 117-125.

Rysman, M. (2009). The economics of two-sided markets [J]. The Journal of Economic Perspectives, 125-143.

Schindler, D., \& Schjelderup, G. (2010). Profit Shifting in Two-Sided Markets [J]. International Journal of the Economics of Business, 17(3), 373-383.

Song, M. (2011). Estimating platform market power in two-sided markets with an application to magazine advertising [J]. The Bradley Policy Research Center Financial Research and Policy Working Paper No. FR 11, 22.

Thomes, T. P. (2013). An economic analysis of online streaming music services [J]. Information Economics and Policy, 25(2), 81-91.

Tsai, I. C., \& Lei, H. S. (2016). The Importance and Satisfaction of Collaborative Innovation for Strategic Entrepreneurship [J]. Eurasia Journal of Mathematics, Science \& Technology Education, 12(3).

Wang, Y. P. (2016). A Study on Kinmen Resident's Perception of Tourism Development and Culture Heritage Impact [J]. Eurasia Journal of Mathematics, Science \& Technology Education, 12(12).

Xu, J. A. (2013). Two-Sided Market Model of Optimal Price Structure for Instant Messenger [J]. Journal of Applied Mathematics.

\section{http://www.ejmste.com}

